\title{
1,4-Phenylenebis[(6,7-dimethoxy-3,4-dihydroisoquinolin- 2(1H)-yl)methanone]
}

\author{
Stanimir Manolov and Iliyan Ivanov* \\ Department of Organic Chemistry, Faculty of Chemistry, University of Plovdiv, 24 Tzar Assen str., Plovdiv 4000, \\ Bulgaria; manolov@uni-plovdiv.net \\ * Correspondence: iiiliyan@abv.bg; Tel.: +359-32-261-349 \\ Academic Editor: Norbert Haider
}

Received: 21 April 2016; Accepted: 23 June 2016; Published: 28 June 2016

\begin{abstract}
The compound named in the title was prepared from $N^{1}, N^{4}$-diphenethylterephthalamide 1 . The resulting bis terephthalamide was subjected to an intramolecular $\alpha$-amidoalkylation reaction with paraformaldehyde in the presence of heterogeneous catalyst $\mathrm{TfOH} / \mathrm{SiO}_{2}$ to obtain 1,4-phenylenebis[(6,7-dimethoxy-3,4-dihydroisoquinolin-2(1H)-yl)methanone]. The structure of the newly synthesized compound was determined using ${ }^{1} \mathrm{H},{ }^{13} \mathrm{C}-\mathrm{NMR}, \mathrm{UV}$, IR and mass spectral data.
\end{abstract}

Keywords: $\mathrm{TfOH} / \mathrm{SiO}_{2} ; \quad \alpha$-amidoalkylation; terephthaloyl chloride; homoveratrylamine; bis terephthalamide

\section{Introduction}

The alkaloids containing an isoquinoline skeleton are one of the largest classes of plant alkaloids which display a broad spectrum of biological activities [1]. In recent years, acid catalysts have increasingly found use as catalytic systems of acid absorbed on silica [2]. In addition to promoting a successful reaction, their ability to be recovered and consistently reused in subsequent reactions identifies them as environmentally friendly "green reagents"[3]. Based on our previous experience of the application of intramolecular $\alpha$-amidoalkylation for the synthesis of isoquinoline compounds, we have successfully obtained 1,4-phenylenebis[(6,7-dimethoxy-3,4-dihydroisoquinolin$2(1 H)$-yl)methanone] using triflic acid absorbed on silica, as a green catalyst, in an intramolecular $\alpha$-amidoalkylation reaction.

\section{Results}

In this work we report the successful synthesis of 1,4-phenylenebis[(6,7-dimethoxy-3,4dihydroisoquinolin-2(1H)-yl)methanone] as shown in Scheme 1.

The starting amide 1 was synthesized through the application of the Saidov [4] synthetic procedure. Based on our previous experience [5], initial cyclization reactions were performed for amide 1 (Scheme 1) using paraformaldehyde in dichloroethane in the presence of the catalytic system of acid absorbed on silica. In our previous experiments we have reported the use of heterogeneous catalytic systems of polyphosphoric acid absorbed on silica as a new "green" agent for the synthesis of Cherylline derivatives [6]. In search of other new "green" agents, we studied the possibility of applying a TfOH $/ \mathrm{SiO}_{2}$ system as a heterogeneous acid catalyst in an intramolecular $\alpha$-amidoalkylation reaction. Triflic acid (TfOH) is termed a "super acid", as it is perhaps one of the most versatile Brønsted acid catalysts that can be used in a vast array of organic reactions. Because of its high corrosiveness and due to the fact that it is a fuming liquid, difficulties remain in storage, transportation, handling and waste disposal that severely restrict their application in industry [7]. 

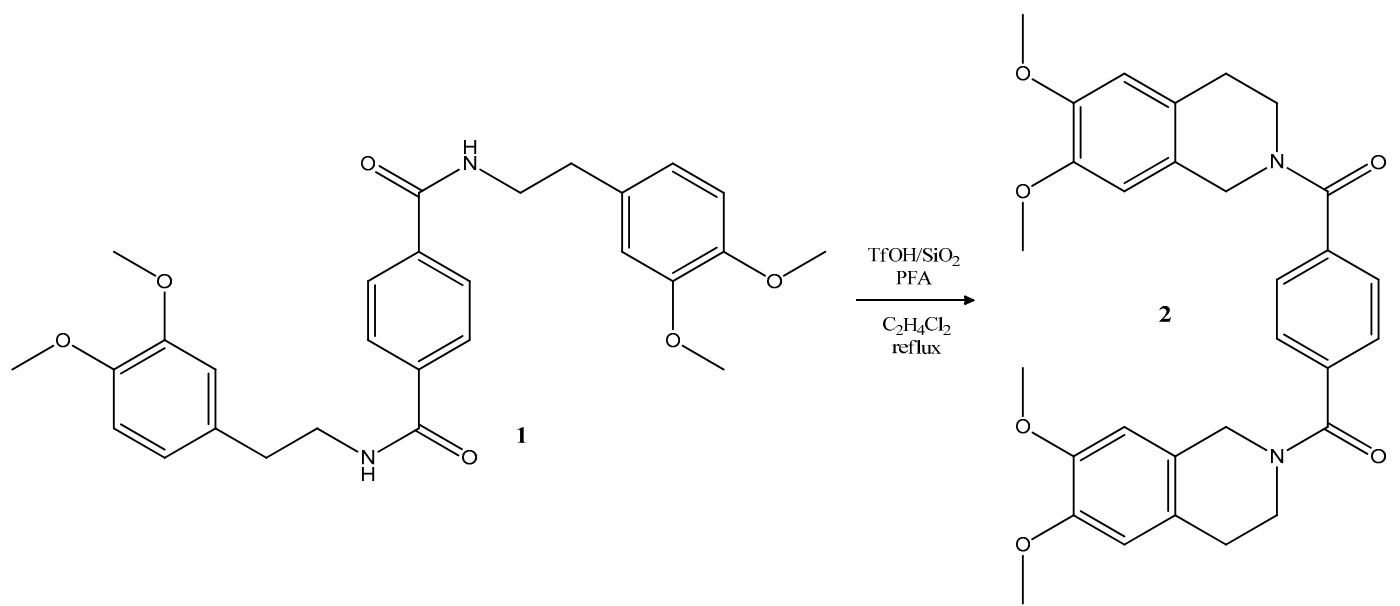

Scheme 1. Synthesis of 1,4-phenylenebis[(6,7-dimethoxy-3,4-dihydroisoquinolin-2(1H)-yl)methanone] 2.

For the cyclization step, to amide 1 (Scheme 1) dissolved in dichloroethane we added paraformaldehyde in excess and $\mathrm{TfOH} / \mathrm{SiO}_{2}$. Compound 2 was successfully obtained by refluxing the reaction mixture for $10 \mathrm{~min}$. After completion of the reaction, the reaction mixture was cooled, and the catalyst was removed via filtration. The solvent was then distilled via rotary evaporator.

Compound 2 was obtained as a light yellow solid (93\% yield) with a melting point recorded at 199-202 ${ }^{\circ} \mathrm{C}$. The UV spectrum exhibited absorption maxima $\lambda_{\max } 203,234$ and $284 \mathrm{~nm}$. The mass of the compound in the HRMS spectrum was found at $[\mathrm{M}+\mathrm{Na}]^{+}, m / z=539.2128$ (Calculated: 539.2158). The signals in the NMR spectrums are doubled due to rotamers in nearly a 1:1 ratio.

\section{Materials and Methods}

All the reagents and chemicals were purchased from commercial sources (Sigma-Aldrich, Sofia, Bulgaria) and used as received. Melting points were determined on a Boetius hot stage apparatus and are uncorrected. The spectral data were recorded on a Bruker Avance II +600 spectrometer (BAS-IOCCP-Sofia, Sofia, Bulgaria). The ${ }^{1} \mathrm{H}-\mathrm{NMR}$ and ${ }^{13} \mathrm{C}-\mathrm{NMR}$ spectra for compound 2 were taken in DMSO at $600 \mathrm{MHz}$ and $150.9 \mathrm{MHz}$, respectively. Chemical shifts are given in ppm relative and were referenced to TMS $(\delta=0.00 \mathrm{ppm})$ as an internal standard with the coupling constants indicated in Hz. The NMR spectra were taken at room temperature (ac. $295 \mathrm{~K}$ ). TLC was carried out on precoated $0.2 \mathrm{~mm}$ Fluka silica gel 60 plates, using diethyl ether $/ n$-hexane $=1 / 1$ as chromatographic system. The catalyst $\mathrm{TfOH} / \mathrm{SiO}_{2}$ was prepared using the procedure detailed by Liu et al. [3].

\section{Synthesis of 1,4-Phenylenebis[(6,7-dimethoxy-3,4-dihydroisoquinolin-2(1H)-yl)methanone] 2}

To a solution of $N^{1}, N^{4}$-diphenethylterephthalamide 1 ( $\left.3 \mathrm{mmol}\right)$ and paraformaldehyde $(5 \mathrm{mmol})$ in $\mathrm{C}_{2} \mathrm{H}_{4} \mathrm{Cl}_{2}(10 \mathrm{~mL})$ was added $0.06 \mathrm{~g}$ of catalyst $\left(\mathrm{TfOH} / \mathrm{SiO}_{2}, 0.5 \mathrm{mmol} / \mathrm{g}\right)$. The reaction mixture was placed under reflux for $10 \mathrm{~min}$. After the completion of the reaction, the reaction mixture was cooled and the catalyst was separated by simple filtration.

1,4-Phenylenebis[(6,7-dimethoxy-3,4-dihydroisoquinolin-2(1H)-yl)methanone] (2). White solid (M.p. 199-202 $\left.{ }^{\circ} \mathrm{C}\right) .{ }^{1} \mathrm{H}-\mathrm{NMR}(600 \mathrm{MHz}, \mathrm{DMSO}) \delta \mathrm{ppm} 2.71(\mathrm{~s}, 2 \mathrm{H}), 2.85(\mathrm{~s}, 2 \mathrm{H}), 3.55$ (m, 2H), 3.73-3.81 $(\mathrm{m}, 12 \mathrm{H}), 3.93(\mathrm{~m}, 2 \mathrm{H}), 4.41(\mathrm{~s}, 2 \mathrm{H}), 4.77(\mathrm{~s}, 2 \mathrm{H}), 6.33(\mathrm{~s}, 1 \mathrm{H}), 6.56-6.61(\mathrm{~m}, 3 \mathrm{H}), 7.44(\mathrm{~s}, 4 \mathrm{H}) ;{ }^{13} \mathrm{C}-\mathrm{NMR}$ (150.9 MHz, DMSO) $\delta$ ppm 146.9, 136.6, 126.4, 126.3, 110.5, 110.3, 108.2, 107.5, 54.9, 48.5, 44.3, 42.5. $\lambda_{\max }, \mathrm{MeOH}: 203,234,284 \mathrm{~nm}$. HRMS (ESI) $m / z$ calcd for $\mathrm{C}_{30} \mathrm{H}_{32} \mathrm{~N}_{2} \mathrm{O}_{6}[\mathrm{M}+\mathrm{Na}]^{+}=539.2158$, found 539.2128. IR (KBr) $v_{\text {max }, ~} \mathrm{~cm}^{-1}: 760 \gamma\left(\mathrm{C}_{\mathrm{sp}}^{2}-\mathrm{H}\right), 847 \gamma\left(\mathrm{C}_{\mathrm{sp}}{ }^{2}-\mathrm{H}\right), 1037 v_{\mathrm{s}}\left(\mathrm{C}_{\mathrm{sp}}{ }^{2}-\mathrm{O}-\mathrm{C}\right), 1207 v_{\mathrm{as}}\left(\mathrm{C}_{\mathrm{sp}}{ }^{2}-\mathrm{O}-\mathrm{C}\right)$, $1442 \delta\left(\mathrm{R}_{2}=\mathrm{N}-\mathrm{CH}_{2}-\right), 1518 v\left(\mathrm{C}_{\mathrm{sp}}{ }^{2}-\mathrm{C}_{\mathrm{sp}}{ }^{2}\right), 1631 \gamma(\mathrm{N}-\mathrm{C}=\mathrm{O}), 2835 \delta_{\mathrm{as}}\left(\mathrm{OCH}_{2}-\mathrm{H}\right), 2933 v_{\mathrm{as}}\left(\mathrm{CH}_{2}\right), 3067 v\left(\mathrm{C}_{\mathrm{sp}}{ }^{2}-\mathrm{H}\right)$.

Copies of all spectra and ESI-HRMS (Figures S1-S5) are provided in the Supplementary Materials. 
Supplementary Materials: The molefiles and the other supplementary materials can be found at http://www.mdpi.com/1422-8599/2016/3/M902.

Acknowledgments: We acknowledge financial support from the fund for scientific research of the University of Plovdiv-НИ15-ХФ-001.

Author Contributions: Both authors contributed equally to both the experimental and writing work.

Conflicts of Interest: The authors declare no conflict of interest.

\section{References}

1. Kamlah, A.; Lirk, F.; Bracher, F. A new approach to 1-substituted $\beta$-carbolines and isoquinolines utilizing tributyl[(Z)-2-ethoxyvinyl]stannane as a C-3, C-4 building block. Tetrahedron 2016, 72, 837-845. [CrossRef]

2. Kaur, M.; Sharma, S.; Bedi, P.M.S. Silica supported Brönsted acids as catalyst in organic transformations: A comprehensive review. Chin. J. Catal. 2015, 36, 520-549. [CrossRef]

3. Liu, P.N.; Xia, F.; Wang, Q.W.; Ren, Y.J.; Chen, J.Q. Triflic acid adsorbed on silica gel as an efficient and recyclable catalyst for the addition of $\beta$-dicarbonyl compounds to alcohols and alkenes. Green Chem. 2010, 12, 1049-1055. [CrossRef]

4. Saidov, A.S.; Levkovich, M.G.; Alimova, M.; Vinogradova, V.I. Synthesis of bis-tetrahydroisoquinolines based on homoveratrylamine and dibasic acids. 2. Chem. Nat. Compd. 2014, 49, 1099-1104. [CrossRef]

5. Venkov, A.; Temnyalova, T.; Ivanov, I. Synthesis of $N, N^{\prime}$-bis(1,2,3,4-tetrahydroisoquinolinyl) dicarboxamides by an intramolecular $\alpha$-diamidoalkylation reaction. Synth. Commun. 1995, 25, 1419-1425. [CrossRef]

6. Manolov, S.; Nikolova, S.; Ivanov, I. Silica-supported polyphosphoric acid in the synthesis of 4-substituted tetrahydroisoquinoline derivatives. Molecules 2013, 18, 1869-1880. [CrossRef] [PubMed]

7. Kumar, D.; Sonawane, M.; Pujala, B.; Jain, V.K.; Bhagat, S.; Chakraborti, A.K. Supported protic acid-catalyzed synthesis of 2,3-disubstituted thiazolidin-4-ones: Enhancement of the catalytic potential of protic acid by adsorption on solid supports. Green Chem. 2013, 15, 2872-2884. [CrossRef]

(C) 2016 by the authors; licensee MDPI, Basel, Switzerland. This article is an open access article distributed under the terms and conditions of the Creative Commons Attribution (CC-BY) license (http://creativecommons.org/licenses/by/4.0/). 